\title{
PREOPERATIVE LIDOCAINE INFUSION FOR THE PAIN MANAGEMENT IN LAPAROTOMY PROCEDURES: A RANDOMIZED CONTROL TRIAL.
}

1. MBBS, FCPS

Assistant Professor

Department of Anesthesiology \&

ICU,

Liaquat University of Medical and Health Sciences Jamshoro.

2. MBBS, FCPS

Assistant Professor

Department of Anesthesia \&

Surgical ICU

Chandka Medical College, Larkana.

3. MBBS, FCPS, M.Sc Pain Medicine

Assistant Professor \& Head

Department of Anesthesiology

Surgical ICU \& Pain Management,

GMC Hospital Sukkur.

4. MBBS, FCPS

Consultant

Department of Anesthetist

Dow University of Health Sciences,

Civil Hospital Karachi.

5. MBBS

Medical Officer

Civil Hospital Karachi,

Correspondence Address:

Dr Sheraz Raza Naqvi.

Civil Hospital Karachi,

drsherazrazanaqvi@gmail.com

Article received on:

10/05/2018

Accepted for publication:

31/08/2018

Received after proof reading:

22/05/2019
Hamid Raza ${ }^{1}$, Ahmed Uddin Soomro², Maqsood Ahmed Siddiqui ${ }^{3}$, Kamlaish $^{4}$, Muhammad Sheraz Raza Naqvi ${ }^{5}$

ABSTRACT... To evaluate the role of pre-operative lidocaine infusion for pain management in laparotomy procedures. Study Design: Prospective double blind randomized control trial. Setting: Tertiary care hospital in Karachi, Pakistan. Period: 8 months duration from April 2017 to November 2017. Materials \& Methods: $N=50$ patients belonging to ASA Classification types I and II were selected to be part of this study. All the patients underwent major abdominal surgeries (laparotomy). The study group received lidocaine $2 \%, 1.5 \mathrm{mg} / \mathrm{kg}$ IV bolus half an hour before induction, followed by an infusion of $1.5 \mathrm{mg} / \mathrm{kg} / \mathrm{hour}$. The anesthesia was induced with fentanyl $3 \mathrm{ug} / \mathrm{kg}$, propofol $2 \mathrm{mg} / \mathrm{kg}$, followed by rocuronium $1 \mathrm{mg} / \mathrm{kg}$ to intubate the patient. Maintenance was done with using $33 \%$ nitrous oxide in oxygen along with $0.8 \%$ of isoflurane. Fentanyl was administered as an infusion initiating prior to the procedure with a maximum dose of $1 \mathrm{ug} / \mathrm{kg} /$ hour and ceasing the infusion half an hour prior to end of procedure. Visual analog scale was used to measure the pain intensity at an interval of twenty minutes during the first hour of the procedure, and at 2,4,8,12,24 and 48 hours after the end of the procedure. If the visual analog scale score was found to be more than 3, 1 to $3 \mathrm{mg}$ of Morphine was administered every ten minutes up to a dose of $0.1 \mathrm{mg} / \mathrm{kg}$ intravenously. A proforma was used to collect data, data was analyzed using IBM SPSS version 21.0. Results: The study was conducted on $n=50$ patients, with a mean age of 38.35 years in the study group and 36.48 years in the control group. The intensity of pain was found to be significantly less in the case group as compared to the control group having a $p$ value of $<0.001$ during the first 48 hours of the procedure. Decreased consumption of morphine was observed in patients in the study group, as compared to the control group with a statistically significant difference, having a $p$ value of less than $<0.05$. In our study we did not observe any side effects related to toxicity levels of lidocaine or morphine. Conclusion: Our study confirms the results of previously done studies, and we found that in our patient population Perioperative lidocaine infusion decreased the post-operative pain experienced by the patient and decreased the need for consumption of analgesics. Thus we conclude that lidocaine infusion perioperatively is an effective pain management modality.

Key words: $\quad$ Analgesic Use, Laparotomy, Lidocaine Infusion, Morphine Consumption, Pain Management.

Article Citation: Raza H, Soomro A, Siddiqui MA, Kamlaish, Naqvi MSR. Preoperative lidocaine infusion for the pain management in laparotomy procedures: a randomized control trial. Professional Med J 2019; 26(6):924-928. DOI: 10.29309/TPMJ/2019.26.05.3598

\section{INTRODUCTION}

Surgeons and anesthesiologists prioritize pain management for patients and it can be a big challenge at times. ${ }^{1}$ There are various methods for pain management such as analgesia, systemic and local anesthesia for which lidocaine is an effective adjunct. Lidocaine is an amide whose mechanism of action is through blocking the sodium channels. It also has a mild analgesic effect. $2,3,4,5,6$ Lidocaine is used to produce regional anesthesia, chronic and acute pain control and anti arrhythmia. The pain control is achieved by infusion. ${ }^{7,8,9}$ Sodium channel blockers have anti nociceptive effects in chronic pain which is influenced by hyperalgesia. ${ }^{10}$ Systemic use of lidocaine preoperatively was shown to be effective in decreasing pain as compared to its postoperatively. ${ }^{11} \mathrm{~A}$ subgroup of nociceptors called the mechanosensitive nociceptors which are known to be involved in maintenance and generation of hyperalgesia are prone to intravenous lidocaine. ${ }^{12,13,14}$ To that extent the aim 
of our study was to examine the effects of lidocaine infusion in acute pain control and its influence on morphine consumption post operatively in laparotomy procedures.

\section{MATERIALS AND METHODS}

The type of study was a prospective double blind randomized control trial, conducted for a period of 8 months duration from April 2017 to November 2017, at a tertiary care hospital in Karachi, Pakistan. The study was approved by the hospitals ethics committee. $\mathrm{N}=50$ patients belonging to ASA Classification types I and II were selected to be part of this study. All the patients underwent major abdominal surgeries. All the patients signed included in the study were above 18 years of age and agreed to be included in the study and signed an informed consent to be part of this study, while patients with hypertension, diabetes mellitus, ischemic heart disease or other uncontrolled medical condition and patients with current substance use issues were excluded from the study.

The patients were divided into two groups, the study group and the control group. The study group received lidocaine $2 \%, 1.5 \mathrm{mg} / \mathrm{kg}$ IV bolus half an hour before induction, followed by an infusion of $1.5 \mathrm{mg} / \mathrm{kg} / \mathrm{hour}$. The anesthesia was induced with fentanyl $3 \mathrm{ug} / \mathrm{kg}$, propofol $2 \mathrm{mg} / \mathrm{kg}$, followed by rocuronium $1 \mathrm{mg} / \mathrm{kg}$ to intubate the patient. Maintenance anesthesia was done with using $33 \%$ nitrous oxide in oxygen along with $0.8 \%$ of isoflurane. Fentanyl was administered as an infusion initiating prior to the procedure with a maximum dose of $1 \mathrm{ug} / \mathrm{kg} / \mathrm{hour}$ and ceasing the infusion half an hour prior to end of procedure. The anesthesiologist and nurses involved were blinded to the groups. Visual analog scale was used to measure the pain intensity at an interval of twenty minutes during the first hour of the procedure, and at 2,4,8,12,24 and 48 hours after the end of the procedure.

If the visual analog scale score was found to be more than 3,1 to $3 \mathrm{mg}$ of Morphine was administered every ten minutes up to a dose of $0.1 \mathrm{mg} / \mathrm{kg}$ intravenously. A proforma was used to collect data, including the dosages of lidocaine utilized and timing of the doses of morphine, side effects experienced by the patient like nausea, light headedness, metallic taste, tinnitus, sedation, circum oral tingling. The concentration of lidocaine in the blood was measured during the procedure and post operatively. Data was analyzed using IBM SPSS version 21.0, mean and standard deviation was used for continuous variables, frequency and percentages was used for nominal/ordinal variables. Student $t$ test was used to compare the various variables including the consumption of morphine and duration of surgery. A p value of less than 0.05 was considered to be statistically significant.

\section{RESULTS}

The study was conducted on $n=50$ patients, with a mean age of 38.35 years in the study group and 36.48 years in the control group. The male to female ratio in the study group was 17:8 and 16:9 in the control group respectively. The ASA classification in the study group was 15 patients in class I and 10 patients in class II while in the control group the ASA classification was 16 patients in class I and 9 patients in class II. The mean duration of surgery in the study group was found to be 92 min in the study group and 93 min in the control group. The visual analog scale scores are graphically shown in Figure-1 which shows the normal curve of pain intensity and the difference between the case and control group can be easily visualized.

The intensity of pain was found to be significantly less in the case group as compared to the control group having a $p$ value of $<0.001$ during the first 48 hours of the procedure. The range of visual analog scale scores was found to be 6 , with the highest value of 7 and lowest of 1 respectively. No patient reported a pain intensity of greater than 7 in both the groups. The Morphine consumption of patients is given in Table-l, which shows a decreased consumption in patients in the study group, with a statistically significant difference, having a $p$ value of less than $<0.05$. In our study we did not observe any side effects related to toxicity levels of lidocaine or morphine. Incidences of nausea and vomiting were similar in both the groups. 


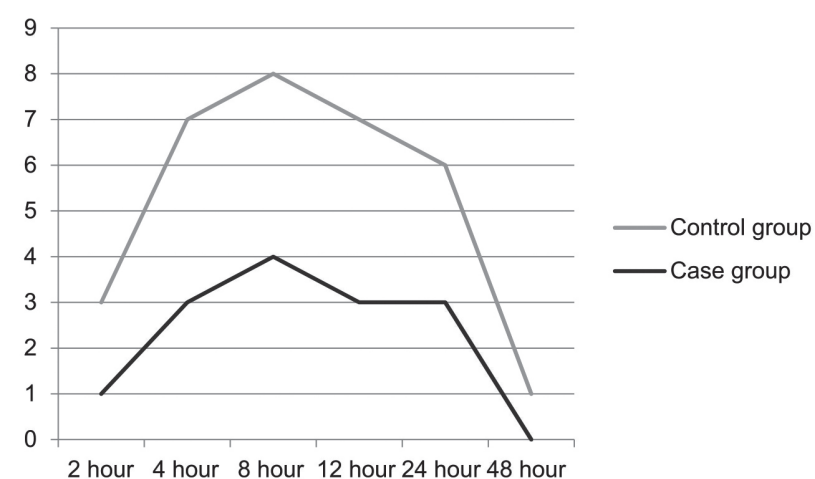

Figure-1. The mean visual analog scale scores over time for the study and control groups.

\begin{tabular}{|c|c|c|}
\hline Variable & $\begin{array}{l}\text { Study } \\
\text { Group }\end{array}$ & $\begin{array}{l}\text { Control } \\
\text { Group }\end{array}$ \\
\hline Mean Age in years & 38.35 years & 36.48 years \\
\hline \multicolumn{3}{|l|}{ Sex } \\
\hline Male & 17 & 16 \\
\hline Female & 8 & 9 \\
\hline \multicolumn{3}{|l|}{ ASA Classification } \\
\hline Class I & 15 & 16 \\
\hline Class II & 10 & 9 \\
\hline $\begin{array}{l}\text { Mean duration of } \\
\text { procedure (mins) }\end{array}$ & $92 \mathrm{~min}$ & $93 \mathrm{~min}$ \\
\hline \multicolumn{3}{|c|}{ Table-I. Patient demographics. } \\
\hline Variable & Study group & Control group \\
\hline \multicolumn{3}{|l|}{$\begin{array}{l}\text { Consumption } \\
\text { of morphine }\end{array}$} \\
\hline 2 hour & $1.0 \mathrm{mg}$ & $2.8 \mathrm{mg}$ \\
\hline 4 hour & $1.3 \mathrm{mg}$ & $3.0 \mathrm{mg}$ \\
\hline 8 hour & $1.7 \mathrm{mg}$ & $3.2 \mathrm{mg}$ \\
\hline 12 hour & $2.0 \mathrm{mg}$ & $3.5 \mathrm{mg}$ \\
\hline 24 hour & $1.3 \mathrm{mg}$ & $2.2 \mathrm{mg}$ \\
\hline 48 hour & $1.0 \mathrm{mg}$ & $1.1 \mathrm{mg}$ \\
\hline
\end{tabular}

\section{DISCUSSION}

In our study we sought to re enforce the results of previously published studies on the effects of lidocaine in acute pain management. Even though in the current literature the exact mechanism of this pain reduction of intravenously administered lidocaine is not well understood, it is postulated that lidocaine acts more as an antihyperalgesic in contrast to other agents which have direct analgesic properties. ${ }^{4,6}$ Small doses of lidocaine affect the mechanosensitive nociceptors through which central sensitization is influenced. Central hyperalgesia is prevented due to the systemic administration of lidocaine. This also leads to a morphine sparing effect caused by a direct inhibition of the N-methyl-D-Aspartate (NMDA) receptor. One major issue to be considered by the anesthesiologists is the blood concentration of lidocaine and its related toxic effects. Previously reported studies indicated towards a wide range of plasma concentrations of lidocaine, a continuous infusion of 1.5 to $2 \mathrm{ug} / \mathrm{ml}$ led to a plasma level of lidocaine between 1.3 to $4 \mathrm{ug} / \mathrm{ml}$, and we used this range to monitor intra operative complications of lidocaine infusion. Pain was evaluated using the visual analog scale in both patient groups from 1 hour post operatively till 48 hours of the procedure. We found significant difference in the patient reported pain levels in the two groups. The $p$ value for the difference in the visual analog scale scores was $<0.001$. For both the groups the pain level was highest between 9 and 17 hours post operatively but the pain level was still lower in the study group as compared to the control group. According to a study by Groudine SB et al they found the morphine consumption was lower in the systemic lidocaine group in their study with mean morphine consumptions of 157 $+/-73 \mathrm{mg}$ in the control group and $103+/-72$ $\mathrm{mg}$ in the lidocaine group respectively. ${ }^{15}$ In our study we found a similar trend of decreased consumption of morphine in the lidocaine group with a $p$ value of $<0.001$, showing a statistically significant difference. According to Cassuto et al administration of a sodium channel blocker half an hour prior to the surgical procedure at $2 \mathrm{mg} /$ min till 24 hours post operatively decreased the post operative consumption of morphine and pain levels experienced by the patient till 48 hours of the procedure. ${ }^{11}$ Postoperative lidocaine infusion does not show any effective analgesic effects. ${ }^{16}$ The hypothesis being that maximum effect of sodium channel blockade is on the nociceptive input during the surgical procedure, thus resulting in decreased levels of pain. Groudine et al report an opioid sparing effect in the early period post procedure ${ }^{17}$, which could be due to their inclusion of trauma cases into their study. In our study we found the opioid sparing effects to continue up to 48 hours post operatively. The Groudine 
studies confirm the effectiveness of lidocaine infusion in production of central hyperalgesia in gastrointestinal procedures.

\section{CONCLUSION}

Our study confirms the results of previously done studies, and we found that in our patient population Perioperative lidocaine infusion decreased the post-operative pain experienced by the patient and decreased the need for consumption of analgesics. Thus we conclude that lidocaine infusion peri-operatively is an effective pain management modality.

Copyright@ 31 Aug, 2018.

\section{REFERENCES}

1. Henrik Kehlet, Jergen H Dahl. Anesthesia, surgery, and challenges in postoperative recovery Anesthesiology 2003; 362:1921-8.

2. Sivrikaya. GU. Multimodal analgesia for postoperative pain management In: Racz G, editor. Pain management current issues and opinions. Rijeka, Croatia: In Tech; 2012. Available from: http://www.intechopen.com/ books/painmanagement-current -issues-and opinions/ multimodal-analgesia- for-management.

3. Mathies EN, Dahl B. Thomsen BA. A comprehensive multimodal pain treatment reduces opioid consumption after multilevel spine surgery. Eur Spine J 2013; 22:2089-96.

4. Power I. Recent advances in postoperative pain therapy. BrJAnaesth2005; 95:43-51.

5. Kehlet H, Dahl JB. The value of multimodal or balanced analgesia in postoperative pain treatment. Anesth Analg 1993; 77:1048-56.

6. Jaffe $\mathrm{JH}$, Martin WR. Opioid analgesics and antagonists. In: Goodman LS, Gilman A, Eds. The Pharmacological Basis of Therapeutics. 6th Ed. New York, NY: Macmillan; 1980:494-534.

7. WallinG; Cassuto J, HogstrOm S. Effects of lidocaine infusion on the sympathetic response to abdominal surgery. Anesth Analg 1987; 66:1008-13.
8. Rimbiick G, Cassuto J, Tollesson PO. Treatment of postoperative paralytic ileus by intravenous lidocaine infusion. Anesth Analg 1990; 70:414-9.

9. Koppert W, Weigand M, Neumann F. Perioperative intravenous lidocaine has preventive effects on postoperative pain and morphine consumption after major abdominal surgery. Anesth Analg 2004; 98: 1050- 5.

10. Kastrup J, Petersen P, DejgardA, Angelo HR., Hilsted $\mathrm{J}$. Intravenous lidocaine infusion--a new treatment of chronic painful diabetic neuropathy? Pain 1987; 28:69- 75.

11. Cassuto J, Wallin 0 , Hegstrom S. Inhibition of postoperative pain by continuous low-dose intravenous infusion of lidocaine. Anesth Analg 1985; 64:971-4.

12. Lamacraf $\mathrm{G}$. The link between acute postoperative pain and chronic pain syndromes. SouthAfr $J$ Anesth Analg 2012; 18:45-50.

13. Rimback 0 , Cassuto J. Tollesson. Treatment of postoperative paralytic ileus by lidocaine. Anesth Analg 1990; 70;414-9.

14. Tikums R, Miliauskas $P$, Samalavi ius N, Zurauskas A, Samalavicius $R$, Zabulis V. Intravenous lidocaine for postoperative pain relief after and assisted laparoscopic colon surgery: A randomized, placebo-controlled clinical trial. TechColoproctol2014; 18:373-80.

15. Groudine SB, Fisher HAO, Kaufman RP Jr. Intravenous lidocaine speeds the return of bowel function, decreases postoperative pain, and shortens hospital stay in patients undergoing radical retropubic prostatectomy. Anesth Analg 1998; 86:235-9.

16. Birch K, Jorgensen J, Chraemmer-Jorgensen B, Kehlet $\mathrm{H}$. Effect of intravenous lignocaine on pain and the endocrine metabolic responses after surgery. Br J Anaesth 1987; 59:721-4.

17. Groudine SB, Fisher HA, Kaufman RPJ. Intravenous lidocaine speeds the return of bowel function, decreases postoperative pain, and shortens hospital stay in patients undergoing radical retropubic prostatectomy. Anesth Analg 1998; 86:235-9. 


\section{AUTHORSHIP AND CONTRIBUTION DECLARATION}

\begin{tabular}{|c|c|c|c|}
\hline Sr. \# & Author-s Full Name & Contribution to the paper & Author $=\mathbf{s}$ Signature \\
\hline 1 & Hamid Raza & $\begin{array}{l}\text { Conceptualization, Write up, } \\
\text { Data collection, Literature } \\
\text { review, Proof reading. }\end{array}$ & \\
\hline 2 & Ahmed Uddin Soomro & $\begin{array}{l}\text { Conceptualization, Write up, } \\
\text { Data collection, Literature } \\
\text { review, Proof reading. }\end{array}$ & \\
\hline 3 & Maqsood Ahmed Siddiqui & $\begin{array}{l}\text { Literature review, data } \\
\text { collection, write up, analysis, } \\
\text { proof reading. }\end{array}$ & \\
\hline 4 & Kamlaish & $\begin{array}{l}\text { Data collection, Write up, } \\
\text { Analysis, Literature review. }\end{array}$ & \\
\hline 5 & M. Sheraz Raza Naqvi & & \\
\hline
\end{tabular}

